F. Reprod. Fert. (1975) 42, 391-394

\title{
DIFFERENT PATTERNS OF ENERGY METABOLISM IN THE RAT AND MOUSE ZYGOTE
}

\author{
H. SPIELMANN \\ Abteilung Embryonal-Pharmakologie, Department of Pharmacology, \\ Freie Universität Berlin, 1 Berlin 33, \\ Thielallee 69/73, West Germany
}

(Received 2nd August 1974)

\begin{abstract}
Summary. The development of rat zygotes in vitro to the two-cell stage occurred if lactate, phosphoenolpyruvate (PEP), pyruvate or oxaloacetate were present in the media. When rat and mouse zygotes were cultured in the same droplet of medium containing lactate or PEP, mouse zygotes did not develop to the two-cell stage but the rat zygotes cleaved.
\end{abstract}

Techniques for the culture of preimplantation mouse embryos have made it possible to clarify the nutritional requirements of the earliest cleavage divisions in this species. The cleavage of the zygote can only take place in vitro when pyruvate or oxaloacetate are present in the culture medium (Biggers, Whittingham \& Donahue, 1967; Whittingham, 1969). Development between the two- and eight-cell stages is supported by lactate, pyruvate, phosphoenolpyruvate (PEP) and oxaloacetate (Brinster, 1965a). This investigation of the energy requirements of the rat zygote was undertaken to determine if the results so far reported for the early mouse embryo are species-specific or are equally relevant for the cleavage stages of other mammalian species. The basic medium for the studies was a Krebs-Ringer bicarbonate solution, modified according to Biggers et al. (1967), with a $\mathrm{pH}$ of 7.2 to 7.4 and an osmolarity of $308 \mathrm{mosmol}$. The embryos were cultured according to the method of Brinster (1963) in 5\% $\mathrm{CO}_{2}$ in air under paraffin oil (Uvasol: Merck A.G. Darmstadt, Germany) in tissue culture dishes (Falcon Plastics: Oxnard, California, U.S.A.) or without oil in the U-shaped wells of Cooke-Mikrotiter testplates (C. A. Greiner, Nürtingen, Germany). Wistar rats (strain SW 72: Winkelmann, Kirchborchen, Germany) were bred under a reversed day/night cycle (dark period from 24.00 to 12.00 hours). Mice (strain NMRI: Schwenke \& Co., Nauheim, Germany) were also kept in an artificial day/night cycle (dark period from 20.00 to 08.00 hours). Females were placed with males for $3 \mathrm{hr}$ (06.00 to 09.00 hours), and pregnant animals were killed at 16.00 hours (mice) or 18.00 hours (rats). Mouse zygotes were collected and the cumulus cells were removed with 150 units (mice) or 400 units (rats) hyaluronidase (Boehringer Mannheim, Germany)/ml according to the method of Biggers et al. (1967). Hyaluronidase can induce parthenogenetic cleavage (Graham, 1970) but even with a dose of 400 units hyaluronidase/ml unfertilized rat eggs did not cleave in media in which fertilized eggs developed to the two-cell stage. The 
number which had undergone first cleavage division in culture was checked after $24 \mathrm{hr}$ for the mouse and after $36 \mathrm{hr}$ for the rat embryos.

Rat embryos were cultured for $36 \mathrm{hr}$ in media containing one of the following energy sources (range of concentrations tested in parentheses): lactate $(0.02$ to $25 \mathrm{~mm})$, pyruvate $(0.02$ to $2.0 \mathrm{~mm})$, oxaloacetate $(0.02$ to $2.0 \mathrm{~mm})$, PEP $(0.02$ to $25 \mathrm{~mm})$, acetate $(0.02$ to $2.0 \mathrm{~mm})$, malate $(0.02$ to $2.0 \mathrm{~mm}), \alpha$-ketoglutarate $(0.05$ to $5.0 \mathrm{~mm})$, citrate $(0.02$ to $20 \mathrm{~mm})$, 2-phosphoglycerate $(0.05$ to $5.0 \mathrm{~mm})$, glucose $(0.5$ to $5.0 \mathrm{mg} / \mathrm{ml})$. Rat zygotes cleaved in media containing pyruvate, oxaloacetate, lactate or PEP. In pyruvate and oxaloacetate, the highest rate of development of rat zygotes occurred at concentrations similar to those tested by Biggers $e t$ al. (1967) with mouse embryos. The cleavage of rat zygotes in lactate and PEP contrasts with the findings so far reported for the mouse zygote. The cleavage of rat zygotes in these four substrates is shown in Table 1 .

Table 1. Cleavage of rat zygotes in vitro in different concentrations of pyruvate, oxaloacetate, lactate and phosphoenolpyruvate

\begin{tabular}{|c|c|c|c|c|}
\hline Concentration (mM) & Pyruvate & Oxaloacetate & Lactate & $\begin{array}{c}\text { Phosphoenol- } \\
\text { pyruvate }\end{array}$ \\
\hline $\begin{array}{r}25 \cdot 00 \\
2 \cdot 00 \\
0 \cdot 20 \\
0.02\end{array}$ & $\begin{array}{c}-\overline{10} \\
82 \pm 10(5) \\
89 \pm 8 \quad(10) \\
* 15 \pm 5 \quad(5)\end{array}$ & $\begin{array}{cc} & - \\
78 \pm 12 & (5) \\
85 \pm 6 & (8) \\
* 10 \pm 5 & (6)\end{array}$ & $\begin{array}{cc}87 \pm 15 & (5) \\
86 \pm 12 & (5) \\
* 17 \pm 8 & (6) \\
0 & (5)\end{array}$ & $\begin{array}{r}78 \pm 13(5) \\
90 \pm 8 \\
* 33 \pm 10(5) \\
0 \quad(4)\end{array}$ \\
\hline
\end{tabular}

The values are the mean percentage of a treatment replicated the number of times shown in parentheses. Twenty zygotes were used in each experiment.

* Significantly different from means at higher concentrations, $P<0.001$.

The rat zygote uses the same four compounds for its development as does the two-cell mouse embryo. Mouse zygotes, however, did not cleave in media containing lactate or PEP as the only energy source. Further data were obtained by incubating rat and mouse zygotes in the same droplet. Since first cleavage occurs earlier in the mouse than in the rat under the present experimental conditions, it was possible to observe the development of the zygotes of the two species after different periods of time (Table 2).

The pyruvate data served as controls. The experiments, using concentrations of 2 mM-lactate and 2 mM-PEP, showed that the numbers of cleaving embryos were never more than the numbers of rat zygotes used in the experiments. Identical results were obtained at a concentration level of $25 \mathrm{~mm}$ for both of these substrates. We hoped to prove that the cleaved and the uncleaved embryos belonged to the two different species on the basis of differences in the lactate dehydrogenase $(\mathrm{LDH})$ isoenzyme pattern, since both rat and mouse preimplantation embryos only contain LDH-1 (Brinster, 1965b; Epstein, Kwok \& Smith, 1971; Engel \& Petzoldt, 1973). At different acrylamide concentrations $(5 \%$ and $7.5 \%)$ as well as at different $\mathrm{pH}$ values of the electrode buffer $(\mathrm{pH}$ $8 \cdot 1$ and $9 \cdot 2$ ), however, electrophoresis with adult tissues revealed that although LDH-2 to -5 isoenzymes of the two species could be separated from one another on acrylamide gels, the LDH-1 isoenzymes could not. The LDH-isoenzyme pattern could not, therefore, prove that the two-cell embryos belonged to one 


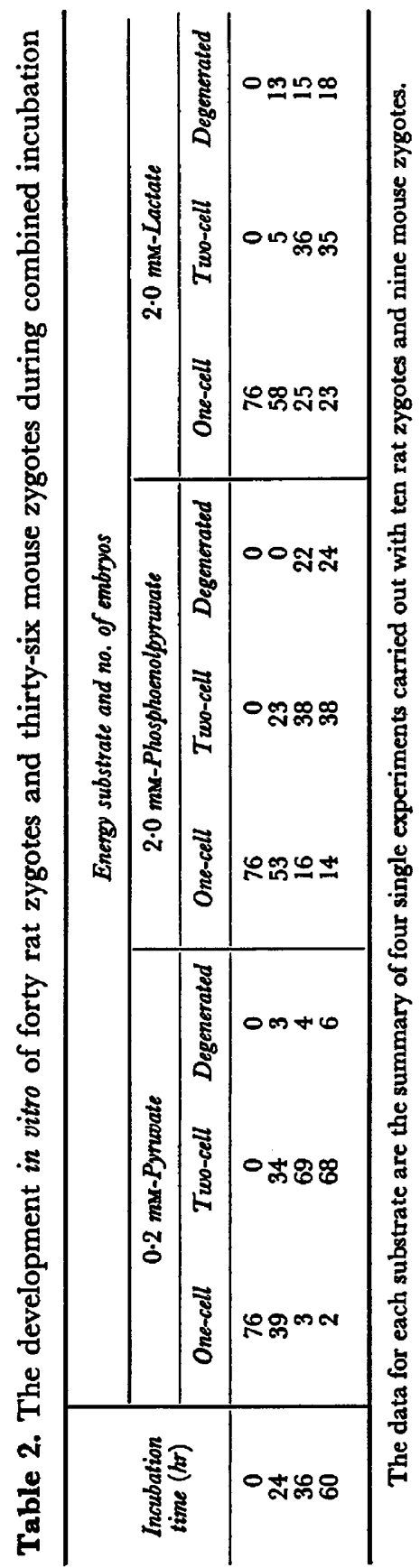


species and the one-cell embryos and degenerated embryos to the other. The inability to culture rat zygotes beyond the two-cell stage even when they were transferred to standard culture media agrees with the results of Biggers et al. (1967) on the development of mouse zygotes in vitro. Mouse zygotes are known to be unable to convert lactate to pyruvate despite their high LDH activity (Brinster, 1965b). Zeilmaker, Hulsmann, Wensinck \& Verhamme (1972) and Sorensen (1972) assumed that the NAD concentration in mouse zygotes was very low because they cleaved successfully in vitro in the presence of lactate and NAD. The same hypothesis has recently been supported by Cross \& Brinster (1973). Our data for the rat make the interpretation of this problem more difficult since the LDH activity in preimplantation rat embryos is much lower than in mouse embryos at the same developmental stage (Brinster, 1967).

The viability of our two-cell rat embryos produced in vitro was not known. Toyoda \& Chang (1974) have cultured two-cell rat embryos from one-cell embryos fertilized in vitro, but they did not develop beyond the two-cell stage. When the two-cell embryos were transferred to the oviducts of pseudopregnant females, however, normal embryos were obtained at term. It seems possible, therefore, that our two-cell rat embryos were also viable. In the mouse, oocyte maturation and the first cleavage division are supported by oxaloacetate and pyruvate. Further investigations are necessary to determine the energy requirements for oocyte maturation in the rat.

I am grateful to Dr Charles J. Epstein (San Francisco) and to Dr Diether Neubert (Berlin) for a stimulatory discussion of the data. This work was supported by grants of the Deutsche Forschungsgemeinschaft given to Sonderforschungsbereich 29 'Embryonale Entwicklung und Differenzierung'.

\section{REFERENCES}

Biggers, J. D., Whittingham, D. G. \& Donahue, R. P. (1967) The pattern of energy metabolism in the mouse oocyte and zygote. Proc. natn. Acad. Sci. U.S.A. 58, 560-565.

Brinster, R. L. (1963) A method for in vitro cultivation of mouse ova from two-cell to blastocyst. Expl Cell Res. 32, 205-208.

BRINSTER, R. L. (1965a) Studies on the development of mouse embryos in vitro. IV. Interaction of energy sources. 7. Reprod. Fert. 10, 227-240.

Brinster, R. L. (1965b) Lactic dehydrogenase activity in the preimplanted mouse embryo. Biochim. biophys. Acta, 110, 439-441.

BRINSTER, R. L. (1967) Lactic dehydrogenase activity in preimplantation rat embryo. Nature, Lond. 214, 1246-1247.

Gross, P. G. \& Brinster, R. L. (1973) The sensitivity of one-cell mouse embryos to pyruvate and lactate. Expl Cell Res. 77, 57-62.

Engel, W. \& Petzoldt, U. (1973) Early developmental changes of the lactate dehydrogenase isozyme pattern in mouse, rat, guinea-pig, Syrian hamster and rabbit. Humangenetik, 20, 125-131.

Epstein, G. J., Kwok, L. \& SMITH, S. (1971) The source of lactate dehydrogenase in preimplantation mouse embryos. FEBS Letters, 13, 45-48.

Graham, G. F. (1970) Parthenogenetic mouse blastocysts. Nature, Lond. 226, 165-167.

Sorensen, R. A. (1972) Problems in oocyte maturation and early development in the mouse. Ph.D. thesis, Yale University.

Toyoda, Y. \& Ghang, M. G. (1974) Fertilization of rat eggs in vitro by epididymal spermatozoa and the development of eggs following transfer. 7. Reprod. Fert. 36, 9-22.

Whitsingham, D. G. (1969) The failure of lactate and phosphoenolpyruvate to support development of the mouse zygote in vitro. Biol. Reprod. 1, 381-386.

Zeilmaker, G. H., Hulsman, W. G., Wensinck, F. \& Verhamme, G. (1972) Oxygen-triggered mouse oocyte maturation in vitro and lactate utilization by mouse oocytes and zygotes. 7. Reprod. Fert. 29, 151-152. 